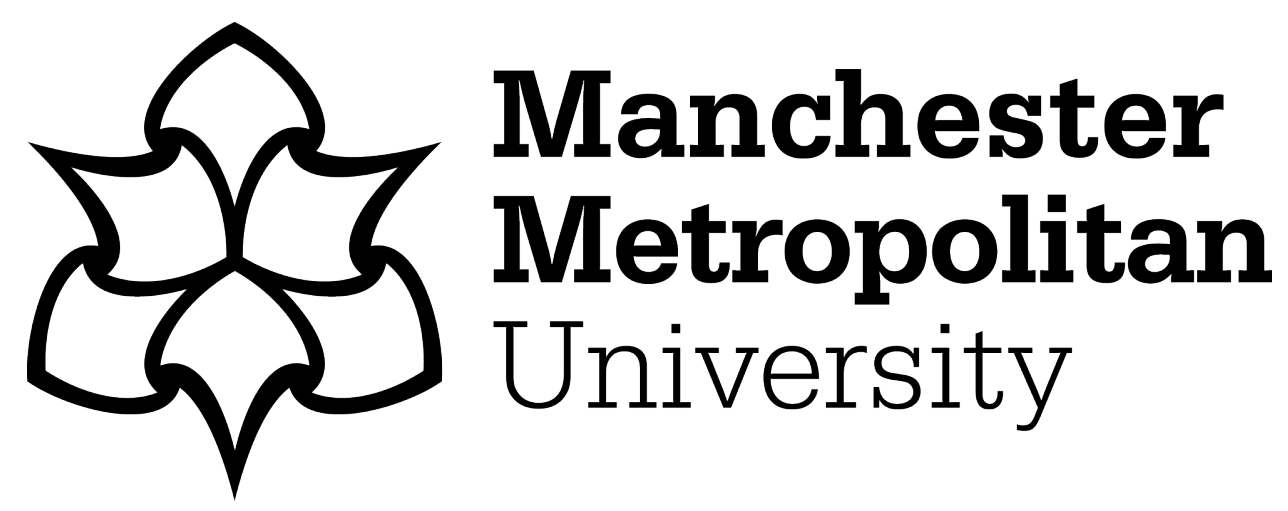

Gallagher, R ORCID logoORCID: https://orcid.org/0000-0002-2096-3889 (2020) Dirty footprints and degenerate archives: Tabitha Nikolai's impure walking sims. Journal of Gaming and Virtual Worlds, 12 (1). pp. 105-122. ISSN 1757-191X

Downloaded from: https://e-space.mmu.ac.uk/628512/

Version: Accepted Version

Publisher: Intellect Books

DOI: https://doi.org/10.1386/jgvw_00007_1

Please cite the published version 


\title{
Dirty footprints and degenerate archives: Tabitha Nikolai's impure walking sims
} Rob Gallagher

https://orcid.org/0000-0002-2096-3889

\begin{abstract}
Tabitha Nikolai's Shrine Maidens of the Unseelie Court and Ineffable Glossolalia are impure specimens of the walking sim. While these are still first-person games that see players exploring eerily underpopulated environments and archiving textual fragments, they are at once more aesthetically reflexive and more referentially dense than many walking sims. Accommodating giant spiders, Weimar sexologists, messageboard trolls and quotations from Roman poetry, Nikolai's unorthodox spins on the 'archival adventure' reflect her interest in queer and trans history and her commitment to interrogating discourses of purity, progress and redemption. Reviewing critical discussions of the walking sim alongside queer, trans and decolonial perspectives on archives, identity and subjectification, the article argues that while walking sims have often been praised for telling emotionally engaging stories, in Nikolai's hands the form assumes different function: that of reckoning with history and exploring subjectivity.
\end{abstract}

\section{Keywords}

walking simulators

artgames

queer game studies

queer theory

trans theory

decolonial theory

archives

sexuality

\section{Introduction}

The practice of interdisciplinary artist Tabitha Nikolai spans installation, performance, writing, sculpture and the production of what she calls 'interactive virtual environment[s]' (Nikolai 2018d). In this article, I want to address two such virtual environments, Shrine Maidens of the Unseelie Court (2018a) and Ineffable Glossolalia (2018b), and to situate them in relation to the 'walking sim' genre. Both are titles animated by ambivalence. Shrine Maidens draws on Nikolai's experiences as a queer and trans ${ }^{1}$ teenager, expressing 'feelings of isolation within suburbia and an ambivalence about online connectivity as a mode of circumventing it' (Nikolai 2018c). Ineffable Glossolalia is 'a dreamy conflation inspired by Borges' Library of Babel ${ }^{2}$ and the German Institut für Sexualwissenschaft' ${ }^{3}$ (Nikolai 2018d), and explores Nikolai's 'ambivalence' about the role of Weimar sexologist Magnus Hirschfeld in trans history ${ }^{4}$ (Musée 2019). Acknowledging the Institute's role in advocating for the

\footnotetext{
${ }^{1}$ The terms Nikolai favours.

${ }^{2}$ A 1941 story in which the Argentine author imagines a library containing every text that has ever been written and ever could be written.

${ }^{3}$ Usually translated as the 'Institute of Sexual Science,' the institute was founded in 1919, and was significant both as a research institution and a place where activists, researchers and members of various queer subcultures lived, worked and socialized.

${ }^{4}$ The widespread adoption of 'trans' as an umbrella term has made it easier to address 'diverse transhistorocal and transcultural practices under the same umbrella', albeit only at the risk of 'imposing an identity category onto pasts in which that identity is anachronistic and onto places where that identity is foreign' (Rawson 2015: 545). While I use terms like 'trans history', I do so with
} 
rights of sexual minorities and gender non-conforming individuals, it also faces up to the fact that many of its members were 'strong proponents of eugenics', manifesting a concern with 'purity' that Nikolai finds echoed in contemporary right-wing discourse (Nikolai 2018d). In terms of their thematic concerns, mechanical conventions and stylistic conceits Shrine Maidens and Ineffable Glossolalia are clearly recognizable as walking sims, part of the genre that Dear Esther (The Chinese Room 2008) and Gone Home (The Fullbright Company 2013) helped to codify and popularize. First-person experiences centred on the navigation of semiotically saturated 3D spaces, they explore the 'domestic chronotope' of the family home (Bowman 2019) and ask players to archive and interpret biographical fragments (Kagen 2019). They also explore issues of gender and sexuality, showing how what has often been read as a queer genre ${ }^{5}$ can speak to trans issues. As games they demonstrate many of the traits that have seen commentators hail the walking sim as a welcome break with gaming's past. Here too, however, Nikolai appears to harbour a degree of ambivalence. While her games follow many of the genre's conventions, they also push at its boundaries, questioning the tendency to see walking sims as inherently and uncomplicatedly progressive. The first part of the article reviews critical and scholarly perspectives on walking sims. Differentiating between story-driven walking sims and those more concerned with aesthetic experimentation, I propose that both variants have become vehicles for fantasies of redemption and progress. This is true both at the level of specific games' plots (which frequently hold out the prospect of making peace with the past through the cathartic revelation of secret histories), and that of critical discussions of the genre (which habitually position it as marking a leap forward, subverting the gauche and grisly first-person shooter to open a space for more expressive and inclusive approaches to digital play). Without denying that the advent of walking sims is cause for celebration, I argue that these fantasies of redemption can obscure the extent to which reckoning with the past may be uncomfortable and ethically compromising - something that Nikolai's ambivalent engagements with the genre insist that players acknowledge.

This discussion lays the groundwork for close analyses of Shrine Maidens and Ineffable Glossolalia. These analyses identify three characteristics that set Nikolai's walking sims apart from similar titles. Firstly, I propose that while all walking sims reckon more or less explicitly with videogame history, Nikolai's games are particularly concerned with the question of what can be salvaged from gaming culture's chequered past. Secondly, I argue that while Nikolai employs expressive techniques familiar from other walking sims, conveying meaning through environmental storytelling and distributing narrative information across constellations of textual fragments, her games push further than most in the direction of fragmentation, incoherence and irresolution. This relates to the third key dimension of her walking sims: the way that they frame identity and subjectivity. Titles like Gone Home are essentially humanistic, aiming for players to become emotionally invested in the life stories of identifiable individual subjects; Nikolai's games, by contrast, are more interested in processes of subjectification. Inviting players to consider how history, technology and culture shape the conditions within which lives are liveable and identities articulable, her walking sims echo the critiques of the humanist subject advanced by exponents of queer, trans, decolonial and posthuman theory.

the proviso that many of the subjects gathered under this banner will have understood themselves and been understood according to different terminological and epistemological frameworks.

${ }^{5}$ On the queerness of the walking sim, see Ruberg (2019a: 200-05). 
The final part of the article looks to these bodies of thought to contextualize Nikolai's aesthetics of assemblage. Incorporating a diverse array of cultural materials and digital assets, her games may be tinged with ambivalence, but they are also unambiguous in their rejection of discourses of purity and progress. Reminding us that 'genre' shares etymological roots with 'gender' and 'genetics' (OED), her walking sims are defiantly impure specimens of the form. Foregrounding the messiness of genealogy, they enable us to recognize the walking simulator as a means of reckoning with history and exploring subjectivity.

\section{Defining the walking sim}

The walking sim genre is founded on a series of constitutive refusals: these are videogames where the player-character cannot die, there is no combat, and conventional forms of competition and challenge are dispensed with (Ruberg 2019a: 201). In a very real sense, the archetypal walking sim is a first-person shooter without the shooting. Dear Esther and Gone Home began as mods of Half-Life 2 (Valve Corporation 2004) and Counter-Strike (Le and Cliffe 1999), respectively, games that originally saw players fending off invading aliens and terrorist aggressors. With the guns removed, these shooters provided the basis for a new ludic form. Centred on exploration and interpretation, it is sometimes seen as a subset of the larger category of 'story exploration games' or 'SEGs' (Green 2017: 167). Derided by some 'hardcore' gamers, walking sims have found favour with players, critics and designers interested in games' expressive and narrative affordances. As Bozdog and Galloway observe, while they do not require 'mastery of complicated control schemes, twitch reflexes, or complex hand-eye coordination', they do demand 'cognitive, critical, and interpretive skills' (2019: 4, 16). There are still criteria for what Jayemanne would call 'felicitous performance' (2017: 16) in these games then; here, however, the ideal player is not an individual capable of vanquishing powerful foes, setting high scores or memorizing complex control inputs, but one adept at recognizing connections, concocting hypotheses and unravelling mysteries. With this rejection of traditional gameplay conventions has come a focus on lower-key settings and stories. Many walking sims focus on the quotidian and the domestic, addressing questions of memory, loss, desire and identity. Some flirt with more fanciful possibilities only to root things more securely in the everyday: while Gone Home plays on our familiarity with gothic novels, 'old dark house' movies and survival horror games, there are no evils resident in the Greenbriar house, just skeletons in the family closet; Firewatch's (Camp Santo 2016) protagonist suspects a conspiracy that turns out to be all in his mind (Kagen 2018). Games like What Remains of Edith Finch (Giant Sparrow 2017) and Everybody's Gone to the Rapture (The Chinese Room 2015), meanwhile, incorporate elements of magic realism and science fiction while retaining a strong sense of place and a focus on character-driven storytelling. Where other genres task players with ending enemy lives, here we often play as detectives or researchers whose task is 'to revivify [...] characters, to put flesh back onto bone' by retracing others' footsteps and collating the biographical scraps they have left behind (Kagen 2019: 12). Such 'archival adventures' (Kagen 2019) offer a refreshing alternative to the models of heroism articulated by Counter-Strike and Half-Life. They do not ask us to save the day, merely to find out what happened. That the stories we uncover frequently concern groups underrepresented in mainstream gaming (women, queers, the elderly and the mentally ill) makes this departure all the more laudable.

One might argue, however, that archival adventures are merely substituting one heroic ideal for another, replacing fantasies of violent domination which what Heather Love has described as fantasies of 'emotional rescue' (2007 33). Love uses this term to describe the dreams that queer researchers often harbour of 'reaching back toward isolated figures in the queer past in order to rescue or save them' - if only by ensuring that their stories are shared (2009: 8). 
While it is tempting to emphasize 'the heroic aspect of the[] work of historical recovery', Love insists that we should acknowledge the ways in which such work can be 'possessive' and 'demanding', more about the fulfilling the desires of researchers than securing justice, understanding or recognition for their subjects (2009: 33). For Love, the alluring notion of the archival researcher as emotional rescuer can lead us to either ignore or look too kindly upon 'texts that resist our advances' and 'figures that refuse to be redeemed' (2009: 8), glossing over aspects of history that remain painful, puzzling or problematic. Putting Love's work into dialogue with Saidiya Hartman's research into archives of slavery, Tavia Nyong'o contends that attempts at rescue and recovery can even end up 'reinscrib[ing] the violence done' to the victims whose stories are brought to light 'in a second violence of retelling' (2019: 61).

These concerns resonate with critical readings of walking sim, particularly those concerned with whether and to what extent it can be considered a queer genre. For Kagen (2019), walking sims may be narratively queer without necessarily being mechanically queer - and vice versa. She argues that Gone Home's ludic linearity betrays the queerness of its plot, proposing that by 'finding all the pieces $[\ldots]$ and organizing them into a neat, teleological narrative' the player-character 'straightens up the narrative of her lesbian sister'; in What Remains of Edith Finch, by contrast, 'the game mechanics [...] fulfil the promise of a queer archival poetics in their multiplicity, a-linearity and lack of defined goals' even as the narrative proves 'relentlessly normative' (2019: 9-10). Pavlounis (2016) and Ruberg (2019b) have also proposed that walking sims often prove 'less queer than [they] might initially appear' (Ruberg 2019b: 1) - not least to the extent that they enable straight players to indulge 'self-congratulatory beliefs about what good LGBTQ "allies" are supposed to feel' (Ruberg 2019a: 180).

The subject of feeling is an important one when it comes to walking sims. Games like Gone Home and Tacoma (The Fullbright Company 2017) are grounded in the extension of sympathetic recognition and understanding to individuals into whose biographies, psyches and homes players are afforded privileged glimpses (Gallagher 2019: 10). But the brand of liberal humanism they evince arguably sits uneasily with queer theory's tradition of interrogating and historicizing 'ideologies of selfhood which seek redemption in and through the individual, especially the idea of a deep and authentic subjectivity' (Dollimore 1991: 78). One of the key reasons such games have been praised as progressive is their success in getting players to invest emotionally in the lives of fictional characters - a department in which videogames have traditionally been considered deficient, at least by comparison with literature and cinema. As Ruberg and Love caution, however, strong feelings are by no means a guarantee of genuine connection and understanding.

Which is not to claim that walking sims entirely ignore the ethical implications of prying into people's pasts and organizing messy lives into neat narratives. Fullbright's games periodically acknowledge the way that "the ruse of "emotional rescue" as justification for recovering stories from the oppressed or obliterated past' can become an alibi for prurience and voyeurism (Nyong'o 2019: 61). And while on the whole they present transparency and openness as unproblematically redemptive and cathartic, both have endings that undercut readings of the player-character as hero; Gone Home's Sam, like the crew of Tacoma, has already rescued herself by the time we discover her fate. Joel Goodwin (2018), meanwhile, has argued that 'Edith Finch's real message' may be that 'contrary to the adage that telling stories is important, telling stories can also be intoxicating and dangerous'. Nikolai's games double down on this aspect of the archival adventure; denying players the opportunity to 
forge emotional connections with identifiable characters, they instead stage encounters with the archive that prove painful, confusing and decentring.

\section{More than mere games?}

We can see, then, how the walking sim as 'story exploration game' or 'archival adventure' can allow players to indulge fantasies of emotional rescue - but also how the form can raise questions about our motivations for delving into the past and our obligations to those whose histories we uncover. But of course, not all walking sims are about collecting narrative fragments strewn across realistic everyday spaces. While the best-known exponents of the genre have tended to follow this pattern, many walking sims are more focussed on atmosphere and audio-visual experimentation. Key texts here include The Night Journey (Viola and GameInnovationLab 2007), which Bailey (2019) has identified as a walking sim avant la lettre, and Proteus (Key and Kanaga 2013), which follows a kind of narrative arc based on the progression of the seasons, but represents a distinct departure from the archival adventure model. Where story-led walking sims are often distributed on platforms like Steam and the PlayStation Store, their more abstract and experimental cousins are frequently encountered in other contexts and spaces. The Night Journey and Proteus have both now been made available for purchase, but they were initially shown in galleries and at festivals. Other games of this kind have been distributed on a pay what you want basis on itch.io, or offered as rewards for Patreon donors - as were Conor Sherlock's murkily atmospheric Last Visit to the Shard (2016) and Kitty Horrorshow's Pente (2016a). The latter evokes early 3D console titles like King's Field (FromSoftware 1994) and Jumping Flash (Exact and Ultra 1995), providing an example of how, where archival adventures tend to rein in commercial games' stylistic excesses, experimental walking sims will often amplify and reflexively foreground them. Catacombs of Solaris (MacLarty 2016) represents another instance of this tendency. A psychedelic exercise in trompe l'oeil texture mapping, the game confines players to a labyrinth covered in disorienting polychromatic patterns. As its readme file explains, ' $[\mathrm{t}]$ he goal of the game is to find your favourite room in the catacombs'. If this directive pokes fun at the goal-orientation of 'real' games, ${ }^{6}$ it also represents a departure from - and perhaps a dig at - the kinds of hermeneutic challenges SEG-style walking sims set players. Where those games can be played for the plot, here exposition takes a back seat to the rarefied pleasures of aesthetic contemplation. It's entirely fitting, at such, that artist Lawrence Lek has given playthroughs of works like Unreal Estate (The Royal Academy Is Yours) (2015) at the avant-garde music venue Café OTO; as his 'speculative simulation' of the prestigious arts institution suggests, these are both games as galleries and (at least in some cases) games for galleries too. ${ }^{7}$

Zimmerman and Huberts consider both types of walking sim variants of the 'ambience action game' (2019: 31). Using Tacoma and Proteus as case studies, they classify the former as an 'explorative game', 'a mitigated form of the ambience action game [...] defined by a specific focus on embedded narrative elements' (Zimmerman and Huberts 2019: 39); Proteus they deem to be an 'awareness game' - 'an intensified form of the ambience action game' where 'the game world allows players to be present in it and to experience the arising atmospheres' (Zimmerman and Huberts 2019: 39). While the designers of explorative games and

\footnotetext{
${ }^{6}$ On the walking sim's challenge to notions of what constitutes a 'real game', see Consalvo and Paul (2019: 109, 125).

${ }^{7}$ Part of a series of 3D recreations of London landmarks, designed as commentaries on the city's 'regeneration' into a neo-liberal playground, Lek's walking sims allude to gentrification, Brexit and climate change through visual shorthand.
} 
awareness games are playing for different stakes, both can be seen as distancing themselves from gaming's commercial mainstream and attempting to do something more thoughtful. While such efforts are undoubtedly welcome, here too it is possible to see the walking sim as a locus of redemptive fantasies: fantasies of taking the base material of the videogame and transmuting it into something less violent and vulgar, more contemplative and reflexive, less industrial and more artisanal. While to indulge these fantasies is to court abuse from gamergate's regressive rearguard, ${ }^{8}$ it also holds the prospect of securing a more prestigious spot in gaming's 'field of cultural production' (Bourdieu 1993).

\section{Paths less taken}

Having reviewed perspectives on the walking sim, it should be easier to see how Nikolai's games are in dialogue with other examples of the genre. Shrine Maidens and Ineffable Glossolalia are not doctrinaire 'explorative games', and nor are they unadulterated 'awareness games'. While they use narrative techniques familiar from archival adventures, they also reflexively engage with retro videogame aesthetics in a manner more reminiscent of 'awareness games'. Like Kitty Horrorshow's Anatomy (2016b) (which plays out in an old dark house but is neither an orthodox archival adventure, an abstract experiment, nor yet a traditional survival horror game), or Squinky's you used to be someone (2017) (an autobiographical walking sim as indebted to the punk collages of Linder Sterling as it is Dear Esther) they are generically oblique, reflecting Nikolai's commitment to an aesthetics of impurity and ambivalence. Exhibited at the Manhattan gallery apexart as part of Dire Jank, a show curated by Porpentine, they are also available as free downloads via itch.io - and speak, as such, to the imbrication of the artworld and academia with avant-garde, indie and DIY gaming culture.

The discourse around walking sims often suggests a desire to move videogames forward, with advocates and detractors alike positioning these games as departures from, if not attacks on, the conventions of mainstream gaming culture. Yet walking sims often bespeak a deep knowledge of and affection for videogame history, whether we think of experimental awareness games playfully reviving outmoded graphical styles, or of the nods to beloved Nintendo titles in Gone Home - a game Fullbright acknowledge is deeply indebted to venerated FPS developer Looking Glass Studios (Mahardy 2015). In Nikolai's work the question of the walking sim's place in gaming history assumes a central importance. Her games show how antagonistic (and, in particular, how toxically transphobic) gaming culture can be, even as they manifest a stubborn loyalty to aspects of that culture which it is tempting to dismiss as embarrassingly juvenile, aesthetically histrionic or ideologically regressive. Transcending mere nostalgia, her use of retro signifiers begs to be read in tandem with her interest in archival research and her critique of eugenics. As I will argue, Shrine Maidens and Ineffable Glossolalia do not just offer a riposte to accounts of the walking sim as an evolutionary leap; they do so as part of a wider-ranging interrogation of the term on which we narrate history and conceptualize progress.

This aversion to teleological thinking also informs her approach to spatial design and storytelling. Nikolai's walking sims are undoubtedly carefully curated 'awareness spaces' (Zimmerman and Huberts 2019: 32), and serve as examples of how digital games have reworked the trope of the 'gallery scene' familiar from earlier artforms (Jayemanne 2017: 23). Traditionally, such scenes have afforded artists opportunities to reflect on the dynamics of signification, representation and interpretation, and Jayemanne reads them as presenting

\footnotetext{
${ }^{8}$ On gamergate and antipathy to walking sims, see Kagen (2017).
} 
two possibilities: in one, the gallery provides the "performative criteria necessary for felicitous discourse within the space', setting parameters within which the suitably schooled visitor may flaunt her erudition and ingenuity by tracing meaningful connections between the individual exhibits (Jayemanne 2017: 61); in the other visitors are confronted with a kind of semiotic 'magma' that overwhelms attempts at comprehension and navigation, dooming visitors to 'wander[ing] indefinitely through a non-linear labyrinth' (Jayemanne 2017: 60). Most SEGs leave a clear breadcrumb trail of clues, ensuring that players can plot a course through the storyworld and piece together a narrative, however lacunary. Playing Shrine Maidens and Ineffable Glossolalia can, by contrast, feel like being cast adrift in a magmatic morass of unfamiliar allusions and cryptic in-jokes. While it is usually clear enough where we are supposed to go, it can be harder to discern what it is all supposed to mean. By forcing players to patch together interpretations in this way, Nikolai's walking sims affirm the patchwork nature of identity and subjectivity. In many archival adventures, the collections of biographical fragments players assemble are presented as our only means of access to what are nonetheless deep, rounded individuals; Nikolai's walking sims, however, challenge the humanistic idea of a subject who pre-exists or extends beyond such traces. In doing so she suggests how suited the walking sims form is to exploring the dynamics of subjectification. To reiterate, then, there are three elements that I see as central to Nikolai's engagement with the walking sim form: her games take up the question of the walking sim's position in videogame history as part of a broader attempt to complicate conceptions of progress; they amplify the tendency towards fragmentation that is already a characteristic of archival adventures; and they do so in order to present subjectification as piecemeal and processual. The next two sections flesh out these claims via close analyses of Shrine Maidens and Ineffable Glossolalia.

\section{Shrine Maidens of the Unseelie Court}

At the centre of Shrine Maidens is a deserted house, complete with kitchen, living room, bathroom and storage room. As this suggests, the game is to some extent another walking sim about family homes and the secrets they harbour - albeit one that employs a different stylistic vocabulary to Gone Home or Edith Finch. This home is located in a strange landscape of dangling 'USB vines', toxic pools and giant spiders, and its bathroom conceals a portal to a subterranean 'grotto zone' where a small island is on the verge of being swallowed by what the game's map identifies as a 'psychic maelstrom'. At the centre of the island we find what appears to be teenage gamer's bedroom. With its desktop PC, dirty mattress, bottled soft drinks and bong, the room tells a spatial story of disaffection, deviancy and addiction. Looking around we can see a poster for industrial band KMFDM, an image of the androgynous Bridget from the fighting game Guilty Gear (Arc System Works 1998), ${ }^{9}$ one of H.R. Giger's portraits of Li Tobler and an issue of Nintendo Power magazine featuring Samus on its cover - the hero who at, the end of Metroid (Nintendo R\&D1 1986), turns out to be a heroine, removing her helmet to reveal a cascade of blonde hair. Above the desk is an ad for Quake III Arena (id Software 1999) depicting a room not unlike - but even grimmer than - the one we are standing in: dominated by a PC bearing the game's logo, rigged with feeding tubes and featuring a toilet in lieu of a chair, it is configured to ensure that the gamer never need leave the keyboard.

Approaching the desk launches an AIM-style chat interface, through which players are engaged in conversation by a user named 'Orp4n3_d4r11n6'. By selecting responses they can advance a branching, looping dialogue that always ends with the player-character falling

\footnotetext{
${ }^{9}$ A boy who was raised as a girl, Bridget fights in a nun's habit.
} 
asleep and Orp4n3 d $4 \mathrm{r} 11 \mathrm{n} 6$ waking them up. This conversation constitutes our initiation into 'the Unseelie Court'. Here Nikolai is referencing Scottish folklore, where fairies fall into one of two camps: the benign and beautiful (if occasionally mischievous) denizens of the 'seelie' or 'summer' court, and their malicious counterparts in the 'unseelie' or 'winter' court. In this world, however, the Seelie Court is a confederation of cisnormative bigots, right-wingers and purity fetishists. Spurning their Unseelie counterparts as 'corruptions of god's perfection', the products of 'permissive parenting, communism' and 'natural dis/order', Orp4n3_d4r11n6 tells us that they deck 'their foetuses in the sacred colours of their gender, lest they become one of us'.

If these lines cast the un/seelie binary in terms of gender and sexuality, it can also be read in terms of approaches to game design. Referring to the Seelie Court as her 'paradoxically ernest [sic] cousins' Orp4n3_d4r11n6 implies that while they are blessed and favoured, they seem loath to appear silly ${ }^{10}-$ a comment that resonates with Nikolai's willingness to incorporate outsized arachnids, raging psychic storms and other such absurdities into her walking sims, a willingness that sets Shrine Maidens apart from many archival adventures. It is possible to see the journey from Quake III's gothic dungeons to Gone Home's Greenbriar house as emblematic of gaming's growing maturity, a process of curbing the first-person shooter's lurid extravagances to retool the genre for slice-of-life storytelling; Shrine Maidens' gameworld, however, suggests that Nikolai is unwilling or unable to put childish ways behind her. Nesting the bedroom inside the grotto inside the bathroom inside the wasteland like a set of Matryoshka dolls, she declines to choose between realism and fantasy. A similar mix of registers characterizes game's writing. Characters speak in a disjunctive, grandiloquently campy mode that veers between eldritch archaisms and bitchy netspeak. Here, chatting online is portrayed as the 'glimmering [of] sigils', a means of claiming sisterhood with 'the vampire Lamia and her lemures; the Queen of Swords; Attis, Consort of Cybele; the Ancient Tzimisce and her rival Ennoia; Echidna, the mother of monsters; the bounty hunter Samus; and thousands of other P[layer] C[haracter]s and N[on-]P[layer]C[haracter]s'. Here, hikikomori shut-ins who voluntarily isolate themselves - are elevated to the status of miko - shrine maidens maintaining divinely sanctioned vigils.

Nikolai's catalogue of 'PCs and NPCs' encompasses avatars of monstrosity, gender deviancy and hard-won wisdom, mythic beings, pagan gods, Nintendo characters and table-top roleplaying lore. It exemplifies a camp strain in gaming culture, which is more amenable than is sometimes supposed to the kinds of 'startling, juicy displays of excess erudition [...] passionate, often hilarious antiquarianism [...] prodigal production of alternative historiographies [...] "over"-attachment to fragmentary, marginal, waste and leftover products [...] [and] disorienting juxtapositions of present with past, and popular with high culture' that Eve Sedgwick identifies with camp (Sedgwick 2003: 150). Sedgwick's account of camp is part of a celebrated defence of 'reparative reading', one that sees her challenging critiques of camp's 'complicity with the status quo' to frame it instead as the expression of a 'reparative impulse' (Sedgwick 2003: 149). For Sedgwick, 'the desire of a reparative impulse $[\ldots]$ is additive and accretive [...] it wants to assemble and confer plenitude on an object that will then have resources to offer an inchoate self' (Sedgwick 2003). Nikolai seems similarly to feel that, in the absence of responsible, rounded representations of gender nonconformity one has to work with what is available, whether that be mythology, videogames or porn. Where Sedgwick characterizes camp as a queer 'survival' strategy (Sedgwick 2003: 150), Nikolai (2018b) portrays 'online platforms' as a 'life line' for isolated trans individuals. As

\footnotetext{
${ }^{10}$ A word deriving, via a complex process of semantic drift, from seely.
} 
this suggests, while there is certainly something silly about the Seelie's Court's portentous self-mythologization ('Lol, innuendo laden small talk and videogames? That's what this secret sect is all about?'), such roleplay can also constitute a deadly serious form of selfdefence.

Indeed, Orp4n3_d4r11n6 seems surprised to get a response from us, having 'thought you kys'. It's never clear whether we have in fact killed ourselves - nor whether 'we' are the same 'you' she initially thinks she is addressing. Perhaps, she speculates, we are just a 'sweet young babe in the woods' who has 'wander[ed] in to take over [the] station' of a 'girl [who] walk[ed] off her post'. While these questions are left unresolved, it is possible to read Shrine Maidens' scenario as a macabre rebuff to the curiosity and hubris of would-be emotional rescuers. Many Gone Home players approach the attic expecting that they will have to rescue Sam - or else retrieve her body. While the revelation that she has already escaped problematizes the idea of the player-character as hero, it also offers a sense of release and resolution that Shrine Maidens is unwilling to provide: here our exploration of the empty house ends with us interred in a bizarre grotto, taking a dead girl's place, trapped in an endlessly looping 'purgatory'. Denying her characters redemption, Nikolai also complicates framings of the walking sim as a genre capable of redeeming videogames as a vehicle for mature, emotionally engaging realist storytelling.

\section{Ineffable Glossolalia}

Ineffable Glossolalia extends Shrine Maidens' exploration of how subjects piece together identities from cultural scraps. The first thing players see when they launch the game is an etching of the Tower of Babel, framed by a curtained window, emitting puffs of black smoke. The first thing they hear is a stuck record - massed masculine voices chanting. Once upon a time, all the peoples of the earth spoke a common language. When they united to build a tower that would reach to the heavens God punished them for their presumption, leaving their glorious creation in ruins and dooming them to mutual incomprehensibility. Opening with a reminder of this myth, Ineffable Glossolalia's first room establishes that this is a game about sifting through wreckage and ruins, searching for meaningful messages amidst the babble. These themes are underscored as we move through the gameworld, with the crackling of the record giving way to the crackling of a pile of burning books, a reference to the destruction of parts of the Institut für Sexualwissenschaft's library and archives in what would be the first of the notorious Nazi book burnings.

The etching of the Tower - by sixteenth-century artist Cornelisz Anthonisz - also establishes Ineffable Glossolalia as an instance of the walking sim as 'a specific awareness space like a museum, an art installation or a gallery' (Zimmerman and Huberts 2019: 36-37). A multimedia archive incorporating a range of images and texts, its gameworld is divided into two halves. In the early rooms paintings by Weimar artists hang alongside medieval annunciations and photographs from the Institute. Passing through a room full of ransacked filing cabinets and an operating theatre, we move into the second set of rooms, where the focus shifts to contemporary digital culture. These rooms feature floating 4 Chan posts, a server farm and walls made from giant web pages. At their centre is a bedroom decorated with the same mattress, PC and posters we encountered in Shrine Maidens. Outside we find ourselves in Berlin's Bebelplatz, re-envisioned here as a lysergic cyberpunk dystopia. 
As players move through this space blocks of text periodically appear before our eyes. Quotations from Catullus, Borges, Max Beckmann, ${ }^{11}$ Hirschfeld and the Hirschfeld Institute's website alternate with, and are incorporated into, what are presumably Nikolai's own texts. In archival adventures, it is usually possible to arrange the materials we find into an orderly sequence of events concerning identifiable characters (however elliptical); with Ineffable Glossolalia, however, the point is less to trace a particular plot than to draw players into what a minotaur-like NPC identified as 'a librarian of Bebelplatz' describes as a system of 'intricately entwined nesting dolls, stories within stories'. In the words of Borges' 'Library of Babel' our task here entails 'looking for lines of meaning among leagues of cacophony', recognizing resonances, cruel ironies and strange coincidences that echo across histories, cultures, bodies and lives.

The idea of a 'librarian of Bebelplatz' is itself a riff on one such strange coincidence: the fact that Orpenplatz, the square where texts from the Institute's archive were incinerated, would later be renamed in honour of the eminent nineteenth-century socialist August Bebel. The Babel/Bebel homophony invites us to read the conflagration in relation to the myth: at a time when it seemed like things were getting better for individuals Hirschfeld would describe as 'sexual intermediaries' (Bauer 2017: 87), queer and trans hopes were wrecked by the rise of fascism. As Bauer notes, while they 'have become synonymous with the Nazi attack on culture' and have been commemorated 'as the moment when Nazi barbarism revealed itself', it is only in retrospect that 'the neat narrative of condemnation by which the book burnings are memorialized' has taken shape (Bauer 2017: 96). By remembering them as attacks on science and culture in general, moreover, contemporary accounts of the burnings often downplay the role of homophobia, transphobia and antisemitism in motivating a campaign that began with an attack specifically targeted at the Institute. Nikolai's game is a response to this double erasure (the destruction of the archive and the elision of the homophobic and transphobic animus behind the attack), but it is no emotional rescue mission. In fact, Nikolai provides a counterpoint to the hagiographic portrayals of Hirschfeld found in some popular histories. As Amin notes, while 'Hirschfeld has largely been remembered as a progressive Jewish sexologist and early homosexual emancipationist who was repeatedly physically assaulted by anti-semites and eventually forced into exile', he was also 'an ardent believer in the beneficial social effects of eugenic policies to guide reproduction, revitalize the worthy, cure sexual abnormalities, and grade individuals on the basis of their evolutionary fitness' (2018: 599). For Amin, Hirschfeld's correspondence suggests that it was the Nazi's methods rather than the aim of 'purification' per se that he objected to (2018: 600). Nikolai foregrounds these complexities. Citing examples of the Institute's eugenicist rhetoric and questionable medical practices, she also incorporates snatches of Hirschfeld's prose that are chillingly reminiscent of the kind of rhetoric used to justify the book burnings ('we want to eradicate lies. [...] True purity is pure truth' decrees one such fragment).

In its refusal to gloss over such troubling resonances Ineffable Glossolalia represents a compelling response to Amin's call to 'develop alternate historical methods for attending to bad objects from the past [...] for parsing the inchoate conditions of what will become transgender and transsexuality but that, at its origins, is barely recognizable as such [...] [and] for assessing the residues of such disturbing histories in the present' (2018: 592). If queer scholars have complained that walking sims too often give rein to straightening teleological drives, here Nikolai seems to be resisting the particular telos that Rosenberg

\footnotetext{
${ }^{11}$ The painter's triptych Departure (1932-35), often interpreted as a response to being forced into exile by the Nazis, hangs in one of the early rooms.
} 
(2018) has called 'endochronology' - the desire among trans communities to claim figures from the past as heroic pioneers, plotting a 'progress narrative of the alignment of sex hormones and subjectivity'. Rather than representing Hirschfeld as 'ahead of his time' or portraying the Nazi attack as a setback in the linear course of queer progress, Nikolai assembles an archive that resists organization into a neat narrative of inheritance; leaving quotations unattributed and images uncaptioned, she makes it difficult to discern the significance of what we are looking at, and to distinguish others' words from her own. ${ }^{12}$ By refusing to name its sources, Ineffable Glossolalia pushes players to do the kind of archival research it thematises, tracking down the texts, images and figures featured. (As our interlocutor in Shrine Maidens jokes 'Lemme Google that for you [...] but srsly, do that on your own time'). That so much of this information is readily available online is a reminder of the degree to which the internet has realized the dream of an ever-expanding universal library. Nikolai is no cyberutopian, however. Ineffable Glossolalia's gameworld is strewn with giant 404 pages attesting to the ephemerality of online texts and communities, and with snippets of messageboard conversation witnessing the internet's role as vector for misinformation and abuse. In the bedroom transphobic posts from 4Chan's LGBT board are scattered across the space. One anon opines that they have come to see trans people as 'hostile Marxist aliens, not even as people, but as something on the level of NPC spiders in a videogame' - a sentiment that evokes Shrine Maidens' giant arachnids while suggesting how invested in reactionary political ideologies certain corners of gaming culture have become. It is tempting to see such posts as evidence that anonymity fuels toxicity - at least until we notice a Tumblr post celebrating Donald Trump's victory over 'sissy cultural Marxism and PC victimhood', apparently submitted using the author's real name.

As this suggests, Nikolai is asking us to compare the 'then' of the German 1930s, with its libraries ransacked by fascists, to the 'now' of the American present, with its server farms circulating alt-right hatespeech. This juxtaposition risks seeming glib and flattening. We should not assume, however, that Nikolai is asserting a one-to-one correspondence. Like the Bebel/Babel homophony, likeness and difference are both at play in this case. It can be both revealing and reductive to compare Hitler to Trump; similarly, it is important to recognize Hirschfeld's place in the 'prehistory' of contemporary trans culture (Amin 2018: 593), but equally important to challenge reductive and anachronistic projections of contemporary values and concerns onto the past. Amplifying the inherent polyvocality and fragmentariness of archival adventures, Ineffable Glossolalia presents players with an intentionally cacophonous multimedia assemblage capable of accommodating such complexities. In the last part of the article, I want to show how this approach aligns with currents in queer, trans and decolonial thought, before addressing its implications for understandings of the walking sim.

\section{Aesthetics of impurity and ambivalence}

Nikolai has described Ineffable Glossolalia as a game 'about feeling the reverberations of archival loss over time, how you have to invent language or steal language from porn or the internet or hentai or whatever to learn to talk about yourself and make yourself' (Seibel 2018). In doing so she positions herself as part of a trans tradition of mixing discursive modes, genres and registers. Motivated by the desire to assemble a vocabulary adequate to

\footnotetext{
${ }^{12}$ The game's itch.io page reads 'Words by: Crystal Castles, Max Beckman, Gaius Valerius Catullus, Heinrich Heine, Magnus Hirschfeld and his institute, Jorge Luis Borges, the Deutsche Studentenschaft, and Tabitha Nikolai' but gives no specifics.
} 
trans experience, such mixing has also been deployed as a means of escaping and exposing the normativity of genres like the autobiography, the medical history and the theoretical study, all of which require trans subjects to articulate their lives and identities according to hetero- and cis-centric templates (Jones 2018; Bornstein 1995; Jacques 2017). This approach is often metaphorised in terms of patchwork and quilting, from Kate Bornstein's 'whirl of leather and rhinestones' (1995: 87) to Stryker's viscerally gothic affirmation of her kinship with Frankenstein's monster (1994), a response to transmisogynist discourses of abjection that resonates with Nikolai's menagerie of vampires, chimaerae and demons, and with her interest in assemblage. Among the artworks featured in Ineffable Glossolalia is Otto Dix's 'War Cripples' (1920), in which the individuals depicted, like the work itself, comprise collages, constituted of grafts, transplants and prostheses. Preciado identifies 'the rehabilitation of maimed soldiers in the interwar period' as a key driver in the development of modes of 'reconstruct[ing] the [...] body' that trans subjects have subsequently turned to (Preciado 2018: 133). Bauer notes that the same surgeon responsible for pioneering vaginoplasty at Hirschfeld's Institute would go on to serve the Luftwaffe and at Dachau (2017: 86-87), while Jones contends that histories of 'glandular expropriation' present 'problem[s] of complicity' that authors like Preciado struggle to adequately address (2018: 6). Here, again, tracing the (pre)history of trans subjectivity brings troubling historical residues to light - though it is vital to acknowledge that cis and straight subjects are also implicated in (though seldom asked to account for) the histories Preciado charts, which are also the histories of oral contraceptives, cosmetic surgeries and treatments for erectile dysfunction and male pattern baldness.

As this suggests, there are reasons to check the impulse to see bricolage as a peculiarly or quintessentially trans mode. By doing so we risk reifying a set of techniques developed precisely to resist reification. And of course, many other subcultures and marginal communities have been drawn to bricolage, sampling and remix as tactical means of repurposing ready-to-hand cultural materials - especially since the rise of digital media, which have made it easier than ever to isolate, replicate, edit and combine fragments. Nikolai's work is very much a product of such digital modularity. Where many gamers spurn so-called 'asset flips' Shrine Maidens and Ineffable Glossolalia are unabashedly heterogeneous hodgepodges of borrowed assets - the sky in the latter even bears the watermark of the 'stock content agency' 123RF. It is important to remember, moreover, that disjunctive aesthetics are not inherently radical or subversive; Puar argues that while certain strains of trans theory have valorized 'piecing' (where the body is presented as an assortment of parts that resist synthesis into a legibly gendered whole) over 'passing' (the attempt to present a coherent male or female persona), the latter can be crucial to survival, especially for poor and non-white trans subjects (2015: 55). While piecing 'appears transgressive', Puar highlights its compatibility with the demands of 'neo-liberal or market economies', where 'mobility, transformation, regeneration, flexibility, and the creative concocting of the body' are valued as part of a generalized 'commodification [...] of plasticity' (2015: 54). Bricolage and assemblage are neither exclusively trans modes, then, nor necessarily progressive ones. It remains illuminating, however, to see Nikolai's games as participating in a playfully trans-affirmative tradition of bricolage, founded on the rejection of purity. As Ineffable Glossolalia makes clear, Nikolai's aesthetic is a response to what she calls discourses of 'volkisch disk defagmetation'. Equating the extermination of 'fags' and other putative degenerates with the defragmentation of a hard disk, this mordant pun offers an example of how Nikolai's commitment to impurity informs her use of language. If the walking sim has always had links to literary forms like the epistolary novel and the gothic romance, her games also betrays the influence of decadent literature, with its lapidary, 
fragmentary, aphoristic style, and its rejection of organic unity and stylistic purity (Teukolsky 2009: 180). There are similarities here with Jones' account of how Preciado borrows from the generic wardrobes of pornography, elegy, autobiography and 'Left theory' in what she represents 'as a kind of drag - a mode of performativity that repurposes the past for the present and future' (2018: 5).

What Jones frames as drag could also be viewed as reparative reading, an attempt to transform otherwise toxic objects into sources of sustenance. Sedgwick famously opposes reparative reading to 'paranoid reading', a critical methodology founded on the assumption that every object, however apparently innocuous or benign, can be shown to be profoundly problematic provided it is analysed in sufficient depth (2003: 130-40). Rather than embracing one or the other, Shrine Maidens and Ineffable Glossolalia vacillate between what Sedgwick calls the reparative and paranoid positions (2003: 150), as Nikolai shows that it is possible to see games like Quake III in at least two lights: yes, we can view them as violent, vacuous, perniciously addictive 'bad objects', but they are also sources of solace, connection and 'respite' (Musée 2019) - not to mention libraries of images, influences, avatars and assets out of which new identities, communities and genres might be constituted.

Such a stance differs crucially from framings of the walking sim as a triumphantly subversive and progressive break from orthodox gaming culture. Seesawing between domestic banality and arcane spectacle, Shrine Maidens presents us with a monstrous hybrid of Quake III and Gone Home, as if to insist that the walking sim cannot simply leave gaming's embarrassing history behind. Played in tandem with Ineffable Glossolalia, the game also attunes us to the fantasies 'of recovery and repleteness' that the walking sim as 'exploration game' promises to indulge, fantasies akin to those that lead researchers back to the archives (Arondekar 2009: 102). The promise of the archival adventure is that of piecing together coherent timelines and heroically bearing witness to the testimony of the hitherto marginalized and ignored. As we have seen, however, this promise is never uncomplicatedly kept; even in those games readiest to indulge the player's curiosity, gaps in the record will necessarily remain. If all walking sims acknowledge this truth to some extent, Nikolai's are particularly keen to confront players with gaps, dead ends and ambiguities.

They also ask players to forego the pleasure of identifying with well-rounded and relatable fictional persons. Nikolai's 'characters' are less discrete individuals than voices patched together out of second-hand scraps. The chaotic spatial collages she walks us through suggest a conception of identity as profoundly relational, citational and performative. Here, there is another echo of Preciado, for whom 'the body is a living, constructed text, an organic archive of human history as the history of sexual production-reproduction in which certain codes are naturalized, others remain elliptical, and still others are systematically deleted or scratched out' (2013: 25). Orp4n3_d4r11n6's references to networks of 'others inside of selves', disavowed by seelie fools who 'stare, like we stepped out of RedTube, out of THEIR browser histories, a manifestation of the internet infernal incarnate', present a similar vision of subjectivity as posthuman archival adventure.

\section{Conclusion}

Drawing from a now-familiar playbook (empty houses, queer comings of age and disaggregated biographical archives), Nikolai's walking sims present the archival past in ways that encourage players to abide with loss and lack, illegibility, incoherence and impurity. Her approach is not without its own drawbacks and blindspots however. Ineffable Glossolalia cannot be accused of nudging players clue by clue towards the crucial missing 
piece, but one wonders how many players managed to draw 'lines of meaning' out of the game's magmatic babble, especially in its incarnation as a virtual reality installation - hardly a set-up amenable to screengrabbing and Googling. It's also somewhat surprising that, for all its referential range and catholicity, many of the images and texts Ineffable Glossolalia cites are by widely esteemed cis men. While it presents a spatiotemporal manifold in which the world of Weimar sexology bleeds into that of contemporary messageboard culture, there are limits to the game's scope and connections that it fails to trace. Other trans historians have gone out of their way to address the extent to which contemporary conceptions of sex and gender bear the imprint of colonialism and racialization. In their accounts of Hirschfeld's legacy, for example, Amin and Bauer acknowledge 'how the emerging homosexual rights activism [of the early twentieth-century] was itself imbricated in everyday racism and colonial violence' (Bauer 2017: 4). In Nikolai's 'awareness space', however, the Institute and the server farm remain cut off from the plantation and the slave ship.

These issues notwithstanding, Nikolai's impure walking sims remain valuable and thoughtprovoking. Even as they attest to the enduring power of fantasies of recovery and redemption, they draw our attention to the kinds of painful truths those fantasies can obfuscate. Here Arondekar's comments on archival research are germane. For her the fact that we inevitably 'look to the past to find, imagine and materialize archives of our own historical desire' means it is unrealistic to expect researchers to resist 'the seductions of historical recovery and access' and the 'mythos of loss and paucity' entirely (2009: 97-98). Her hope, however, is that we can move away from 'the notion of an object that would somehow lead to a formulation of subjectivity: the presumption that if a body is found, then a subject can be recovered' (2009: 3). Instead, she suggests, we should work towards 'an understanding of the processes of subjectification made possible (and desirable) through the very idiom of the archive' (2009: ). As Nikolai's games show, this is a task for which the walking sim is already proving ideally equipped.

\section{References}

Amin, Kadji (2018), 'Glands, eugenics, and rejuvenation in man into woman: A biopolitical genealogy of transsexuality', TSQ: Transgender Studies Quarterly, 5:4, pp. 589-605.

Arc System Works (1998), Guilty Gear, Yokohama: Arc System Works.

Arondekar, Anjali R. (2009), For the Record: On Sexuality and the Colonial Archive in India, Durham, NC and London: Duke University Press.

Bailey, Andrew Remington (2019), 'Shifting borders', Press Start, 5:2, pp. 125-36. Bauer, Heike (2017), The Hirschfeld Archives, Philadelphia: Temple University Press, http://www.oapen.org/download?type=document\&docid=628406. Accessed 1 August 2019. Bornstein, Kate (1995), Gender Outlaw: On Men, Women, and the Rest of Us, New York, NY: Vintage Books.

Bourdieu, Pierre (1993), The Field of Cultural Production: Essays on Art and Literature, New York, NY: Columbia University Press.

Bowman, Dean (2019), 'Domesticating the first-person shooter', Press Start, 5:2, pp. 15075.

Bozdog, Mona and Galloway, Dayna (2019), 'Worlds at our fingertips: Reading (in) What Remains of Edith Finch', Games and Culture, 2 May 2019, pp.1-20, Doi:

10.1177/1555412019844631. Accessed 20 May 2019.

Campo Santo (2016), Firewatch, Portland: Panic.

The Chinese Room (2008), Dear Esther, Portsmouth: The Chinese Room. (2015), Everybody's Gone to the Rapture, San Mateo: Sony Computer

Entertainment. 
Consalvo, Mia and Paul, Christopher A. (2019), Real Games: What's Legitimate and Not in Contemporary Videogames, Cambridge, MA: MIT Press.

Dollimore, Jonathan (1991), Sexual Dissidence, Oxford: Oxford University Press.

Exact and Ultra (1995), Jumping Flash, San Mateo: Sony Computer Entertainment.

FromSoftware (1994), King's Field, Tokyo: FromSoftware.

The Fullbright Company (2013), Gone Home, Portland: The Fullbright Company. (2017), Tacoma, Portland: The Fullbright Company.

Gallagher, Rob (2019). 'Volatile memories: Personal data and post-human subjectivity in The Aspern Papers, Analogue: A Hate Story and Tacoma', Games and Culture, 15 April 2019, pp.1-15, Doi: 10.1177/1555412019841477. Accessed 30 December 2019.

'Genre, n.' (2019), OED Online, Oxford: Oxford University Press,

https://www.oed.com/view/Entry/77629. Accessed 2 September 2019.

Giant Sparrow (2017), What Remains of Edith Finch, West Hollywood: Annapurna

Interactive.

Goodwin, Joel (2018), 'On Edith Finch', Electron Dance, 23 February,

http://www.electrondance.com/on-edith-finch/. Accessed 30 December 2019.

Green, Amy M. (2017), Storytelling in Video Games: The Art of the Digital Narrative, Jefferson, NC: McFarland.

Horrorshow, Kitty (2016a), Pente, Kitty Horrorshow.

- (2016b), Anatomy, Kitty Horrorshow.

Id Software (1999), Quake III Arena, Santa Monica: Activision.

Jacques, Juliet (2017), 'Forms of resistance: Uses of memoir, theory, and fiction in trans life writing', Life Writing, 14:3, pp. 357-70.

Jayemanne, Darshana (2017), Performativity in Art, Literature, and Videogames, New York:

Springer Berlin Heidelberg.

Jones, Sophie A. (2018), 'The biodrag of genre in Paul B. Preciado's Testo Junkie: Sex, drugs, and biopolitics in the Pharmacopornographic Era', Feminist Encounters: A Journal of Critical Studies in Culture and Politics, 2:2, pp.1-2, Doi:10.20897/femenc/3887. Accessed 30 December 2019.

Kagen, Melissa (2017), 'Walking simulators, \#GamerGate, and the gender of wandering', in J. Eburne and B. Schreier (eds), Nerds, Wonks, and Neocons, Bloomington: Indiana University Press, pp. 249-74. (2018), 'Walking, talking and playing with masculinities in Firewatch', Game

Studies, 18:2, http://gamestudies.org/1802/articles/kagen. Accessed 30 December 2019.

- (2019), 'Archival adventuring', Convergence, 6 May 2019, pp.1-14, Doi:

10.1177/1354856519847875. Accessed 5 July 2019.

Key, Ed and Kanaga, David (2013), Proteus, Cumbria: Ed Key and David Kanaga.

Le and Cliffe (1999), Counter-Strike, Bellevue: Sierra Studios.

Lek, Lawrence (2015), Unreal Estate (The Royal Academy is Yours). London: Lawrence Lek. Love, Heather (2007), Feeling Backward: Loss and the Politics of Queer History, Cambridge, MA and London: Harvard University Press.

MacLarty, Ian (2016), Catacombs of Solaris, Melbourne: Ian MacLarty.

Mahardy, Mike (2015), 'The Looking Glass philosophy behind Gone Home', Polygon, 6

April, https://www.polygon.com/features/2015/4/6/8315901/looking-glass-gone-home.

Accessed 30 December 2019.

Musée (2019), 'Walk through "Ineffable Glossolalia" with Tabitha Nikolai', Musée

Magazine, 26 March, https://museemagazine.com/features/2019/3/26/walk-through-

ineffable-glossolalia-with-tabitha-nikolai. Accessed 31 August 2019.

Nikolai, Tabitha (2018a), Shrine Maidens of the Unseelie Court. Portland: Tabitha Nikolai. (2018b), Ineffable Glossolalia. Portland: Tabitha Nikolai. 
(2018c), 'Shrine Maidens', tabithanikolai.com, https://tabithanikolai.com/ShrineMaidens/targetText=This\%20iteration $\% 20$ explores $\% 20$ feelings $\% 20$ of, way $\% 20$ can $\% 20 \mathrm{be} \% 2$ 0highly\%20therapeutic. Accessed 2 September 2019.

(2018d), 'Ineffable Glossolalia', tabithanikolai.com,

https://tabithanikolai.com/Ineffable-Glossolalia. Accessed 2 September 2019.

Nintendo R\&D1 (1986), Metroid, Kyoto: Nintendo.

Nyong'o, Tavia (2019), Afro-Fabulations: The Queer Drama of Black Life, New York, NY:

New York University Press.

Pavlounis, Dimitrios (2016), 'Straightening up the archive: Queer historiography, queer play, and the archival politics of Gone Home', Television \& New Media, 17:7, pp. 579-94.

Preciado, Paul B. (2013), Testo Junkie: Sex, Drugs, and Biopolitics in the

Pharmacopornographic Era, New York: Feminist Press.

(2018), Countersexual Manifesto: Subverting Gender Identities, New York:

Columbia University Press.

Puar, Jasbir K. (2015), 'Bodies with new organs: Becoming trans, becoming disabled', Social Text, 33:3\&124, pp. 45-73.

Rawson, K. J. (2015), 'An inevitably political craft', TSQ: Transgender Studies Quarterly, 2:4, pp. 544-52.

Rosenberg, Jordy (2018), Confessions of the Fox, London: Atlantic Books.

Ruberg, Bonnie (2019a), Video Games Have Always Been Queer, New York: New York University Press.

(2019b), 'Straight paths through queer walking simulators: Wandering on rails and speedrunning in Gone Home', Games and Culture, 7 March, pp.1-21, Doi:

10.1177/1555412019826746. Accessed 9 September 2019.

Sedgwick, Eve Kosofsky (2003), Touching Feeling: Affect, Pedagogy, Performativity,

Durham, NC and London: Duke University Press.

'Seely, adj.' (2019), OED Online, Oxford University Press,

https://www.oed.com/view/Entry/174808. Accessed 2 September 2019.

Seibel, Brendan (2018), 'Tabitha Nikolai's virtual worlds explore trans identity and social isolation', I-D, 12 November, https://i-d.vice.com/en_us/article/vbam8m/tabitha-nikolaiimmersive-digital-art-trans-identity. Accessed 30 December 2019.

Sherlock, Conor (2016), Last Visit to the Shard, Essex: Conor Sherlock.

Squinky (2017), you used to be someone, Montreal: Squinky.

Stryker, Susan (1994), 'My words to Victor Frankenstein above the village of Chamounix:

Performing transgender rage', GLQ: A Journal of Lesbian and Gay Studies, 1:3, pp. 237-54.

Teukolsky, Rachel (2009), The Literate Eye: Victorian Art Writing and Modernist Aesthetics, Oxford: OUP.

'Unseely, adj.' (2019), OED Online, Oxford University Press,

https://www.oed.com/view/Entry/217702. Accessed 2 September 2019.

Valve Corporation (2004), Half-Life 2, Bellevue: Valve Corporation.

Viola, Bill and GameInnovationLab (2007), The Night Journey. Los Angeles:

GameInnovationLab

Zimmermann, Felix and Huberts, Christian (2019), 'From walking simulator to ambience action game', Press Start, 5:2, pp. 29-50.

Notes

1. The terms Nikolai favours.

2. A 1941 story in which the Argentine author imagines a library containing every text that has ever been written and ever could be written. 
3. Usually translated as the 'Institute of Sexual Science' the institute was founded in 1919, and was significant both as a research institution and a place where activists, researchers and members of various queer subcultures lived, worked and socialized.

4. The widespread adoption of 'trans' as an umbrella term has made it easier to address 'diverse transhistorical and transcultural practices under the same banner', albeit only at the risk of 'imposing an identity category onto pasts in which that identity is anachronistic and onto places where that identity is foreign' (Rawson 2015: 545). While I use terms like 'trans history', I do so with the proviso that many of the subjects gathered under this banner will have understood themselves and been understood according to different terminological and epistemological frameworks.

5. On the queerness of the walking sim, see Ruberg (2019a: 200-05).

6. On the walking sim's challenge to notions of what constitutes a 'real game', see Consalvo and Paul (2019: 109, 125).

7. Part of a series of 3D recreations of London landmarks, designed as commentaries on the city's 'regeneration' into a neo-liberal playground, Lek's walking sims allude to gentrification, Brexit and climate change through visual shorthand.

8. On gamergate and antipathy to walking sims, see Kagen (2017).

9. A boy who was raised as a girl, Bridget fights in a nun's habit.

10. A word deriving, via a complex process of semantic drift, from seely.

11. The painter's triptych Departure (1932-35), often interpreted as a response to being forced into exile by the Nazis, hangs in one of the early rooms.

12. The game's itch.io page reads 'Words by: Crystal Castles, Max Beckman, Gaius Valerius Catullus, Heinrich Heine, Magnus Hirschfeld and his institute, Jorge Luis Borges, the Deutsche Studentenschaft, and Tabitha Nikolai' but gives no specifics. 